\title{
Field performance of shallow recharge well
}

\author{
Edy Susilo, ${ }^{1, *}$,Suripin ${ }^{2}$, and Suharyanto ${ }^{3}$ \\ ${ }^{1}$ Doctoral Program Student of Civil Engineering Diponegoro University, Indonesia \\ ${ }^{2}$ Professor of Civil Engineering Diponegoro University, Indonesia \\ ${ }^{3}$ Lecturer of Doctoral Program of Civil Engineering Diponegoro University, Indonesia
}

\begin{abstract}
The technical calculation of the need for recharge wells to reduce peak floods has not been fully supported yet the need for recharge wells in big cities especially in Indonesia is very urgent. Some recharge well methods are Horton, Sunjoto, HMTL-ITB, Ministry of Public Works, Ministry of Forestry, Indonesian National Standard, Association for Rainwater Storage and Infiltration Technology, and California Storm-water Quality Association. The hypothetical test of recharge wells at the depth and texture of a particular soil is different from the observed infiltration recharge hence it needs to have a field test of recharge wells for different soil texture. With good diameter, soil permeability, and water depth variables, it is expected that the infiltration recharge equation in the well can be empirically better suited to the performance of the recharge wells. Keywords: recharge wells, performance, diameter, and permeability.
\end{abstract}

\section{Background}

Human population| in the urban centers of developing countries brings about| change in the land use and watershed response to the rain. The problem in almost every city is increased floods and declining groundwater availableness. In the Indonesian government Regulation number 13/2017 referred to in the Regional Space plan it is required to apply zero delta Q policy. Efforts to reduce the flood discharge and increase water infiltration into the soil are accomplished with recharge water wells. Applied technical calculations for the reduction of peak flood discharge requires the number of recharge wells, depth, and diameters for a given soil type very much required.

\section{Literature review}

Several calculations of recharge water wells used are Horton, Sunjoto, HMTL-ITB formulas, Ministry of Public Works, Ministry of Forestry, Indonesian National Standards Association for Rainwater Safe-keeping and Infiltration Technology, and California Stormwater Quality Affiliation.

The use of Horton's empirical formulas for the recharge wells dimensions by Elizar [1] and Agus [2] is not totally justifiable despite the use of predetermined infiltration data (fc).

* Corresponding author: 123edysusilo@gmail.com 
Infiltration performed by recharge water wells mainly in full condition due to hydrostatic pressurized water.

The temperament equation of HMTL-ITB, the Ministry of Forestry, the SNI amount 032453, and the Association for Rainwater Safe-keeping and Infiltration Technology (ARSIT) according to Sunjoto [3] is not an appropriate dimensional analysis basic principle.

In Minnesota Urban Small Sites BMP Manual for Infiltration Trench the developed equation is actually more appropriate for normal water ponding not for impregnation.

The essential formula of compression in the soil was proposed by Forchheimer [4] as follows:

$$
q_{0}=F K h
$$

with:

$$
\begin{array}{ll}
\mathrm{qo} & =\text { absorption recharge }\left(\mathrm{m}^{3} / \mathrm{sec}\right) \\
\mathrm{F} & =\text { geometric factor of recharge wells }(\mathrm{m}) \\
\mathrm{K} & =\text { permeability of soil }(\mathrm{m} / \mathrm{sec}) \\
\mathrm{h} & =\text { water depth }(\mathrm{m})
\end{array}
$$

Relating to equation (1), the recharge in the well of the recharge is proportional to the angles, soil permeability, and normal water depth. In addition, Geometric factors developed by several researchers since 1930, have also been studied by Sunjoto [5] with \{a lengthy unit. The observation of the recharge well of the water depth by Susilo [6] follows the \{condition\} of the parabolic curve. According to van Schilfgaarde et al [7] hydraulics of perforated water pipe can be complicated because of non-linearity of the recharge well curve for certain soils which need to be empirically discovered. According to Darcy's regulations, the flow discharge by using a cross section $\mathrm{A}$, the hydraulic conductivity of soil $\mathrm{K}$, and the length of movement $\mathrm{L}$ are formulated by an equation [8]:

or

$$
Q=K A\left(\frac{d h}{d l}\right)
$$

$$
Q / A=K\left(\frac{d h}{d l}\right)
$$

The quantities Q, A, K, and dh for the recharge well are all clearly measurable, but $\mathrm{dl}$ is unknown in length. Then the above equation can be written:

$$
Q / A=f(K, h)
$$

where $\mathrm{h}$ is the water level in the well, and $\mathrm{Q} / \mathrm{A}$ is the absorption recharge per unit area obtained from the measurement.

\section{Methodology}

Pipes with a diameter of $10 \mathrm{~cm}, 20 \mathrm{~cm}, 30 \mathrm{~cm}, 40 \mathrm{~cm}$, and $50 \mathrm{~cm}$ and a length of 2 meters are inserted into the ground vertically for the absorption tests of the five recharge holes at 6 different ground locations. The absorption course is performed at time periods of 1 minute to five minutes. The ground testing was performed in the soil mechanics research laboratory $y$ a method based on the percentage of ground grain passing through sieve \#200with. The absorption per unit area is obtained by dividing the absorption recharge by the area of pipe cross used $(\mathrm{Q} / \mathrm{A}$. The relationship between $\mathrm{Q} / \mathrm{A}$ and the water level is obtained by the regression formula for every single recharge well. The implementation of 
field performance of recharge well studies conducted by following the following flow-chart diagram in Figure 1.

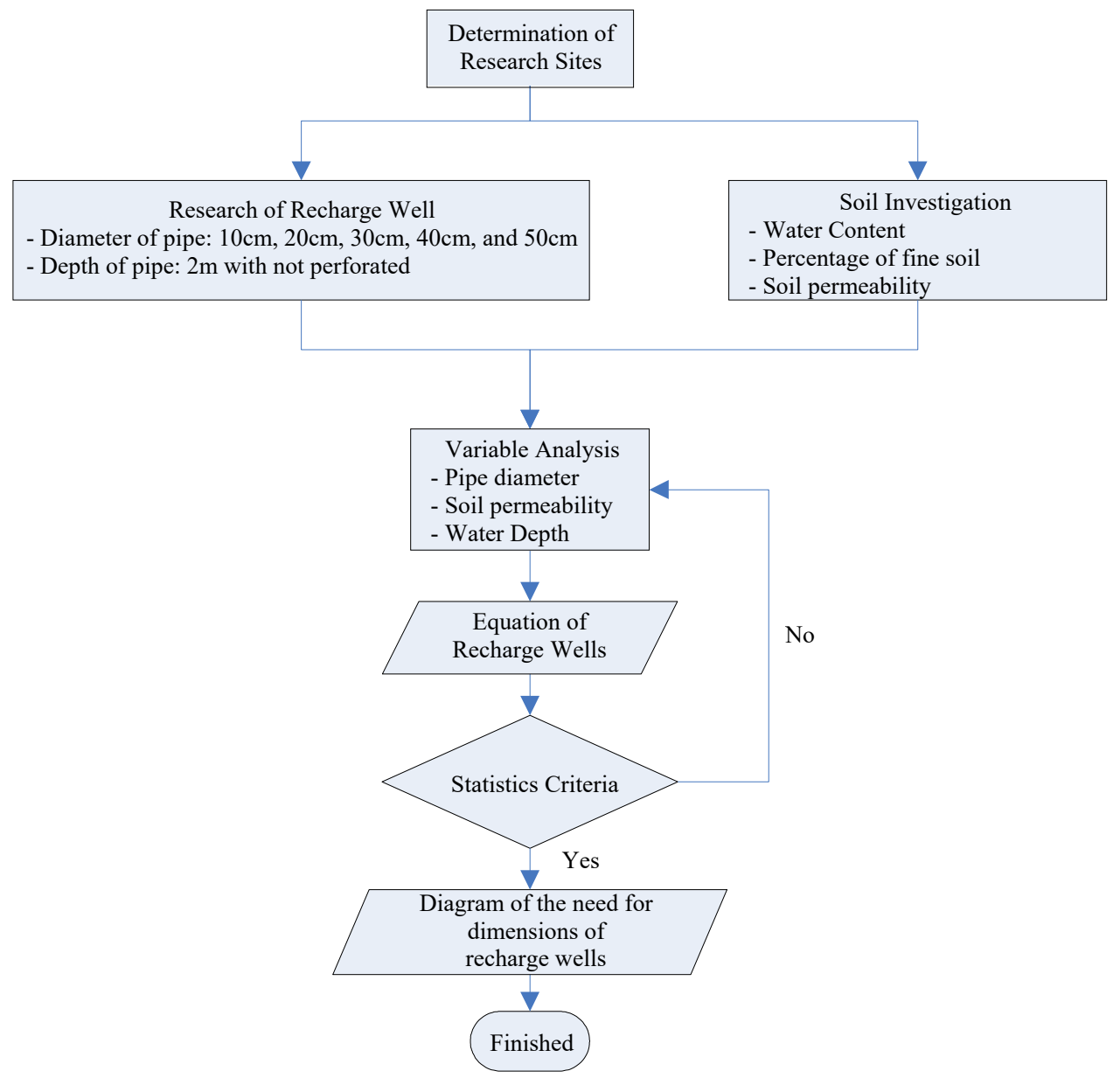

Fig. 1. Flow chart of research method.

\section{Results and discussion}

Soil characteristics of the location of the recharge well point are as follows:

Table 1. Soil characteristics.

\begin{tabular}{|c|c|c|c|}
\hline No. & $\begin{array}{c}\text { Water Content } \\
\mathbf{( \% )}\end{array}$ & $\begin{array}{c}\text { Percentage of Soil } \\
\text { Passing Sieve \# 200 (\%) }\end{array}$ & $\begin{array}{c}\text { Soil Permeability } \\
\text { (mm/day) }\end{array}$ \\
\hline 1. & 26,43 & 50,45 & 16,72 \\
\hline 2. & 36,18 & 66,20 & 5,73 \\
\hline 3. & 37,27 & 51,33 & 3,92 \\
\hline 4. & 12,37 & 59,15 & 2,69 \\
\hline 5. & 22,31 & 57,03 & 2,67 \\
\hline 6. & 28,29 & 56,48 & 2,00 \\
\hline
\end{tabular}


With relatively small soil normal water content, the observation of the infiltration of the wellbore is filled with water content until the condition is saturated more or less for one hour. Percentage passing through the No. 200 filter is more than $35 \%$, according to AASHTO standards classified as silt-clay materials. According to Fetter (1994) cohesive sediment with low conductivity, permeability is assessed by a falling head.

The graph of the absorption at each of the recharge wells per unit area $(\mathrm{Q} / \mathrm{A})$ to the water height $(\mathrm{H})$ can be seen in Figure 2.

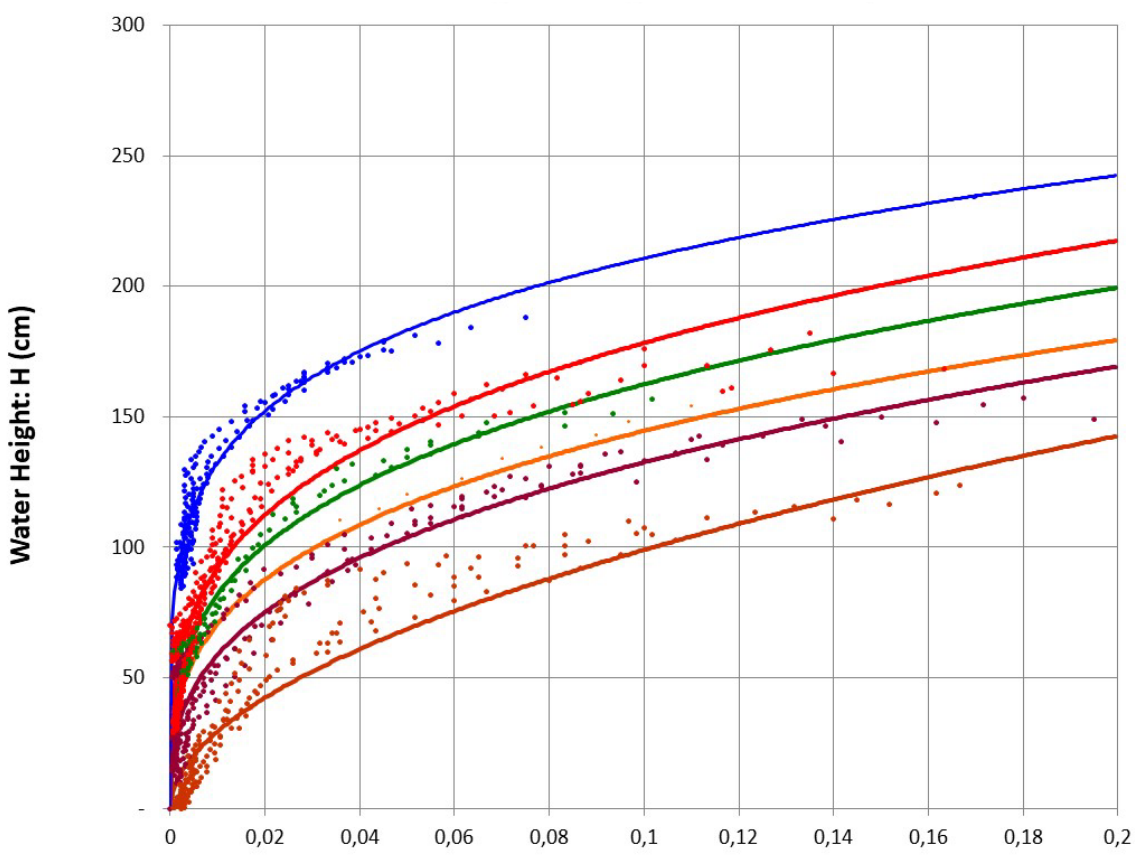

Recharge per unit area : Q/A (cm/sec)

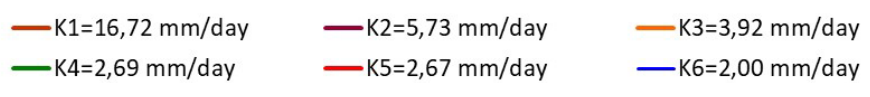

Fig. 2. Plotting the absorption recharge to the water level.

From Figure 1 it can be seen that the absorption capacity of recharge wells is illustrated in the form of parabolic curves sequentially from bottom to top of the larger soil permeability. For each type of soil, the higher the water depth, the discharge rate per unit area is greater. This graph is important for users of recharge wells to determine their dimensions as desired by the reduction of flood discharge in a catchment area.

The steps for using the graph above are as follows:

1. Investigate the soil permeability of the well location

2. Calculate the discharge that will be reduced by a recharge well (Qr) based on hydrological and hydraulic analysis

3. Plan the number of wells to be used (n)

4. Calculate the absorption recharge of a well $(\mathrm{Q}=\mathrm{Qr} / \mathrm{n})$

5. Plan the well diameter to be used

6. Calculate the discharge value per unit area (Q / A)

7. Drag the vertical line upward until it intersects with the appropriate soil permeability curve. If nothing is exactly the same, extrapolation can be done.

8. Drag the horizontal line to get the required depth of well. 
9. If no suitable recharge well dimension of the technical standard is attained, then repeat again the steps from step number 3.

To further facilitate the use of graphs, the horizontal axis $(\mathrm{Q} / \mathrm{A})$ is plotted in logarithms as can be seen in Figure 3.

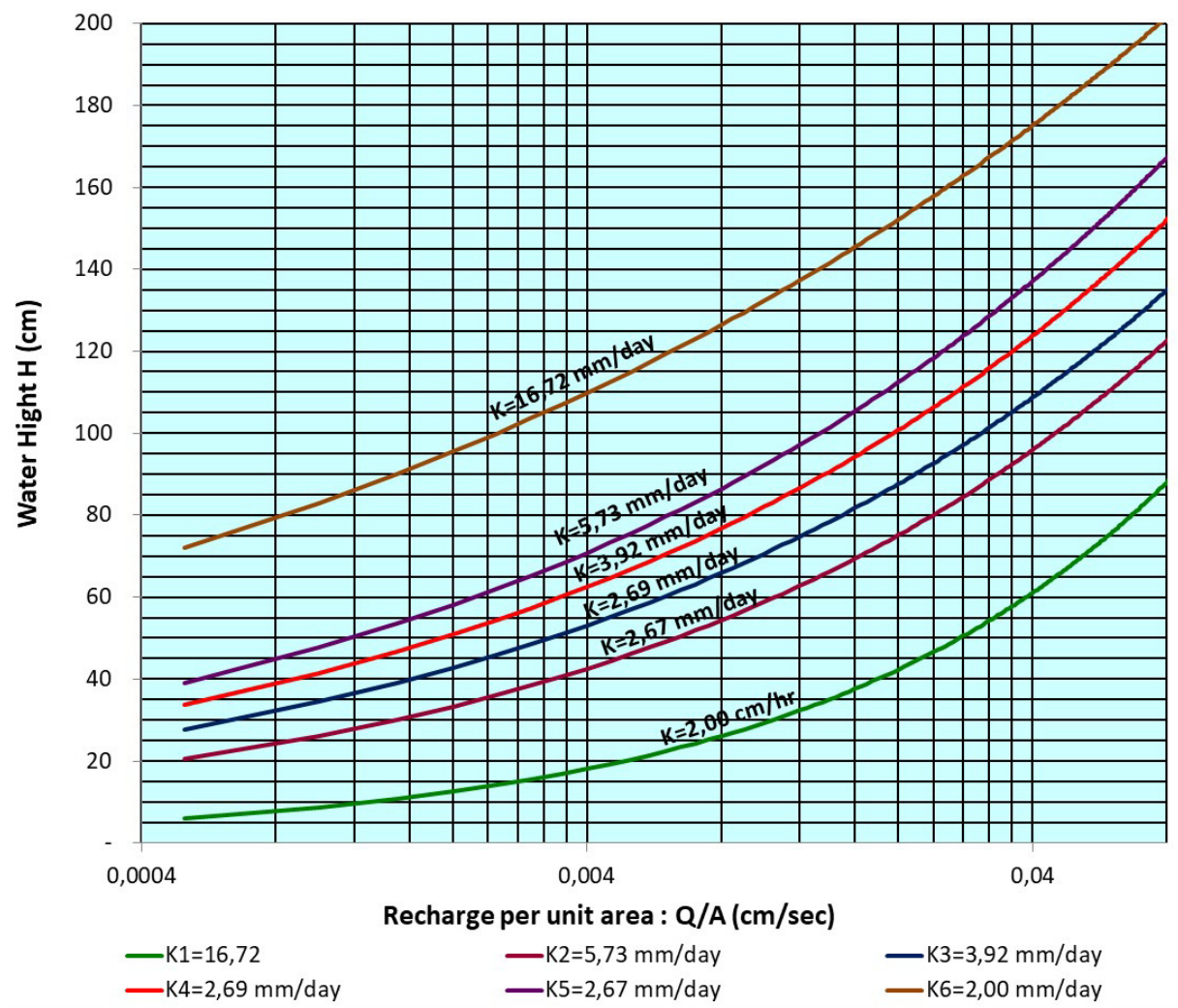

Fig. 3. The relationship of water height to the discharge per unit of recharge well.

\section{Conclusion}

1. The relationship between the recharge per unit of well cross-sectional area to water height is in the form of a parabolic curve

2. Recharge wells are proportional to cross-sectional area and soil permeability

3. Absorption of recharge wells with nonperforated walls is relatively low, so it needs to be innovated with greater absorption.

\section{References}

1. C. W. Fetter, Appl. Hydgeo., Prent. Hall, Upper Saddle Riv., New Jersey (1994)

2. E. Susilo, Kaj. Emp. Sum. Res. pd Tnh Silt, Tek., Vol. XII No. 2, (2017)

3. Elizar dan A. Yolly, An. Laj Inf. Sum. Pers. di PB Meng. Met. Hor., MTS, Vol. XI, (2011)

4. Forchheimer, Hydraulik, Leipzig, Berlin, B.G. Teubner (1930)

5. S. Agus, dan S. Anang S., Pen. Uk. Res. Berd. L. R. CHI, J. MST, Vol. 6 No. 1, (2005). 
6. Sunjoto, Tek. Drain. Pro-Air, JTSL, FT-UGM, Yk (2011).

7. Sunjoto, Tek. Konsv Air pd Kws Pem, MT, Ed. No. 2 Th XI (1989a)

8. van Schilfgaarde, J., ed., Drain. for Agrt., Agr. Ser. No. 17, Amrc. Soc. of Agr., Mad, WI. (1974) 